\title{
Readers' reality-driven and plot-driven analyses in narrative comprehension
}

\author{
DAVID N. RAPP \\ Tufts University, Medford, Massachusetts \\ and \\ RICHARD J. GERRIG \\ State University of New York, Stony Brook, New York
}

\begin{abstract}
We suggest that when readers experience narratives, their expectations about the likelihood of narrative events are informed by two types of analyses. Reality-driven analyses incorporate real-world constraints involving, for example, time and space; plot-driven analyses incorporate concerns about outcomes that emerge from the plot. We explored the interaction of these two types of analyses in the application of temporal situation models. Participants read stories in which the final episode occurred after a minute time shift (i.e., "A minute later ...") or hour time shift (i.e., "An hour later...”). Our experiments assessed participants'judgments and reading times for statements describing the state of events (e.g., the possibility that characterscould carry out particular behaviors) following each type of time shift. Experiments 1A and 1B demonstrated that readers are appropriately sensitive to the real concomitants of time shifts. Experiments 2A and 2B demonstrated, even so, that plot-driven preferences modify judgments and reading times away from reality-drivenexpectations. Our results have implications for the role of the reader in theories of narrative comprehension.
\end{abstract}

In the novel Thunderball (Fleming, 1961), James Bond finds himself at the mercy of an underwater assassin. Time is running out:

Again the butt of the [spear] gun crashed down on his head. Now the water was full of black smoke, heavy, stringy stuff that clung to the glass of his mask. At last it cleared ... the gun was coming up again, slowly, agonizingly, as if it weighed a ton, and the bright sting of the spear showed at its mouth .... Bond couldn't get his limbs to obey. They felt like lead. He shook his head to clear it, but still his hands and flippers moved only half consciously, all speed gone. Now he could see the bared teeth around the other man's rubber mouthpiece. The gun was at his head, at his throat, at his heart. Bond's hands crept up his chest to protect him while his flippers moved sluggishly, like broken wings, below him. (p. 130)

Readers' expectations for the outcome of this scene may be informed by two sets of constraints. On the one hand, a reality-driven analysis would suggest that, given Bond's current physical condition, he will be unable to outmaneuver the gunman's spear. However, a plot-driven analysis

This material is based on work supported by National Science Foundation Grants IRI-9711974, ITR0082602, and IIS-9817484. We thank Susan Brennan, Mark Aronoff, and Brenda Anderson for their insightful advice during the development of this project. We also thank Holly Taylor, Sid Horton, Emily Durbin, Rolf Zwaan, and two anonymous reviewers for helpful comments on the manuscript. Please address correspondence to D. N. Rapp, Department of Psychology, 490 Boston Avenue, Tufts University, Medford, MA 02155 (e-mail: drapp@perseus. tufts.edu). of the scene supports a second, more positive outcome for Bond. Given readers' fervent desire that Bond prevail over his (and the world's) enemies, they may never give up hope that Bond will, somehow, devise a way to escape the spear gun.

This moment from Thunderball illustrates how the different analyses readers can undertake at the same narrative juncture can lead them to anticipate opposite outcomes. We use the term analysis to suggest that readers are, in some fashion, taking stock of the state of a narrative world at a particular moment. Readers' reality-driven analyses are guided by appropriately general expectations about properties of the real world, such as ordinary constraints of space, time, and human behavior. In the Thunderball example, readers should have preexisting notions about how fast Bond can move relative to a spear fired from a gun. In the real world, a human being could not hope to outswim such a weapon. By contrast, readers' plot-driven analyses need not be constrained by physical or behavioral reality. Authors often create circumstances in which readers become strongly committed to particular narrative outcomes. Readers' plot-driven analyses will yield, as their products, conceptualizations of what readers hope or prefer will happen at a particular narrative moment. In the case of Thunderball, readers may hope that Bond will escapeno matter how dire the "reality" of his situation. This plotdriven analysis may partially be informed by expectations concerning Bond's propensity for escaping from dangerous situations. However, as we will describe in this article, a plot-driven analysis need not be informed by past expe- 
rience with specific characters. The goal of this article is to demonstrate how reality- and plot-driven analyses interact during readers' narrative experiences.

Many theories of text comprehension have taken as their starting point readers' reality-driven analyses of texts. These theories suggest that readers construct mental representations, termed situation models, that encode the normal passage of time, the normal organization of space, and normal expectations for how characters and objects interact. Situation models facilitate the comprehension of text, allowing readers to form inferences (Glenberg \& Mathew, 1992; Glenberg, Meyer, \& Lindem, 1987; Perrig \& Kintsch, 1985; van Dijk \& Kintsch, 1983). Theorists have attempted to outline the processes involved in constructing multidimensional situation models. One model that has gained empirical support is the eventindexing model (Taylor \& Tversky, 1997; Zwaan, Langston, \& Graesser, 1995; Zwaan, Magliano, \& Graesser, 1995). According to this model, readers encode and retrieve indices for the spatial, temporal, causal, intentional, and protagonist-object relations in a text. These indices conform to reality-driven expectations about the natural physical and social limits of characters and events.

Research on situation models has confirmed the view that readers' narrative experiences are structured through appropriate expectations about reality. Consider studies that have examined how readers encode information about the passage of time in a narrative (Graesser, Kassler, Kreuz, \& McLain-Allen, 1998; Magliano, Miller, \& Zwaan, 2001; Radvansky, Zwaan, Federico, \& Franklin, 1998; Rich \& Taylor, 2000; Rinck, Hähnel, \& Becker, 2001; Zwaan, 1996; Zwaan, Madden, \& Whitten, 2000). In one project, for example, participants read texts containing time shifts (e.g., a moment later, an hour later, or a day later) (Zwaan, 1996). Consider the following story:

Today was the grand opening of Maurice's new art gallery. He had invited everybody in town, who was important in the arts. Everyone who had been invited, had said that they would come. It seemed like the opening would be a big success. At seven o'clock, the first guests arrived. Maurice was in an excellent mood. He was shaking hands and beaming. A moment/an hour/a day later, he turned very pale. He had completely forgotten to invite the local art critic. And sure enough, the opening was very negatively reviewed in the weekend edition of the local newspaper. Maurice decided to take some Advil and stay in bed the whole day. (p. 1207)

After reading a version of the text, readers were asked to indicate whether a particular word (e.g., beaming) had appeared in the story. Their recognition latencies increased when the story included longer versus shorter time shifts. Participants also took longer to read texts and answer questions from stories containing longer time shifts. These effects of time shifts follow from realitydriven analyses. Specifically, time shifts of longer duration usually move story events out of a particular temporal setting; readers shift focus to new scenarios. This shift in reader focus appears to reduce the accessibility of information from the earlier episode.
Results of this type provide an indication as to how reality-driven analyses facilitate the construction and application of situation models for ordinary features of the world, such as the normal passage of time. However, researchers have often neglected plot-driven analyses of texts in their theories of situation models (Gerrig, 1993). This omission is somewhat problematic. Situation models are supposed to serve as representations of "the state of affairs described in a text" (Zwaan \& Radvansky, 1998, p. 162). Presumably, the products of what we are calling plot-driven analyses would be an important component of that "state of affairs." For example, the event-indexing model suggests that readers index characters' intentions (Zwaan, Langston, \& Graesser, 1995; Zwaan, Magliano, $\&$ Graesser, 1995). We suggest that readers encode not only characters' intentions, but also their own preferences with respect to those intentions. In the Thunderball excerpt, the fellow with the spear gun very much intends to kill Bond. However, we suspect that the modal reader hopes that the assassin will fail.

In our view, readers may undertake plot-driven analyses any time a narrative has a plot that is sufficiently rich to engage readers' interest in particular outcomes. Readers are at liberty, at any time, to take stock of the distance between the current state of a narrative and an outcome they desire. Authors have available a range of techniques to prompt reader involvement of this type. Authors may, for example, create empathy for particular characters, so that readers wish for the characters to prevail. Authors may create suspense so that readers are prompted to contemplate a range of possible outcomes. Authors may disrupt the timeline of narrated events, through flashbacks or flashforwards, so that readers maintain representations from multiple perspectives. Each of these author practices is likely to lead readers to engage different types of processes or representations. We label them all plot-driven analyses, because we locate the origin of the processes and representations in readers' strategic contemplation of the possibilities of the plot.

Previous research has supported this suggestion that readers' plot-driven responses have an impact on text processing and representation (Allbritton \& Gerrig, 1991; Prentice, Gerrig, \& Bailis, 1997). For example, one set of experiments demonstrated effects of readers' outcome preferences. Participants read stories that began with outcome statements such as "Sue was elated to hear her name as the winning entry was announced" (Allbritton \& Gerrig, 1991, p. 620). The texts continued with story material that created reader preferences with respect to such outcomes: e.g., "Sue didn't really care about the award, but she did want the money. She plagiarized an essay from a source no one would recognize and turned it in." At the end of each story, the participants were asked to verify the story's actual outcome. The preferences that the stories imparted had a consistent effect on the time course with which readers were able to verify the outcomes: When readers' preferences were nonnormative (i.e., they were encouraged to construct a preference for a negative outcome), they took more time to verify actual story out- 
comes. These results demonstrate that what readers wish to have happen has an impact on their representations of what actually transpired in a text.

For the present experiments, we wished to make a more direct contrast between the exigencies of reality and plot. We took as our domain readers' assessments of the likely concomitants of the passage of time. We begin by demonstrating the impact of reality-driven analyses in this domain. Consider the following story:

1. Billy was waiting outside the St. Louis Cardinals' stadium, with a baseball card for Mark McGwire to sign. 2. Billy stood in a large group of fans waiting to meet the future hall of fame player.

3. McGwire's fans were holding all types of baseball memorabilia.

4. One child was holding a baseball.

5. Another adult was holding a large framed photograph of McGwire.

6. Billy looked at his perfect condition card.

7. He really wanted to get that autograph.

8. McGwire appeared and said hello to the fans.

9. A minute later he got into his limo and rode off.

After reading this brief text, what are readers likely to think about the likelihood that Billy obtained an autograph? Presumably, readers are able to do some mental simulation (cf. Kahneman \& Tversky, 1982; see also Barsalou, 1999, for a recent discussion of mental simulation) to provide at least a tentative answer to this question. They are unlikely to imagine that Billy could acquire McGwire's autograph in a minute. Rather, they are likely to expect that Billy would be unable to get the autograph, given the large crowd of fans and McGwire's quick exit. Suppose, however, that Sentence 9 read as follows:

9. An hour later he got into his limo and rode off.

In this case, readers should be better able to simulate mentally a course of events that would allow Billy to get the autograph. This mental simulation is what we mean, in this case, by a reality-driven analysis. Readers, presumably, are able to use their knowledge of the real-life durations of activities to simulate what could happen in a minute or an hour. Thus, our initial prediction is that, consistent with earlier research on temporal encoding in situation models, readers will make accurate judgments about what can transpire in a minute versus an hour.

However, we also predict that those judgments will be affected by the preferences generated through plot-driven analyses. Consider our earlier example with a change in Sentence 2:

1. Billy was waiting outside the St. Louis Cardinals' stadium, with a baseball card for Mark McGwire to sign. 2. Billy had been diagnosed with terminal cancer, and his lifelong dream was to meet his baseball idol.

3. McGwire's fans were holding all types of baseball memorabilia.

4. One child was holding a baseball.

5. Another adult was holding a large framed photograph of McGwire.
6. Billy looked at his perfect condition card.

7. He really wanted to get that autograph.

8. McGwire appeared and said hello to the fans.

9. A minute later he got into his limo and rode off.

In this version of the story, we intended readers to sympathize with Billy's plight. Accordingly, we intended readers to encode the preference that Billy manage to get McGwire's autograph. In the contrasting case, we intended readers to encode the preference that Billy not get the autograph:

2. Billy was a dishonest collectibles dealer who would overcharge children when they bought sports cards from him.

How do these preferences affect readers' judgments about the likelihood of outcomes? We propose that readers' preferences can affect their mental simulations. In mental contemplation, the activities that ought to take more than a minute or less than an hour (according to a reality-driven analysis) can be contracted or lengthened, or made less or more precise, to fit the readers' plot-driven needs.

Our research had two phases. In the first phase, we sought to demonstrate that readers encode and retrieve temporal information from situation models using realitydriven analyses of texts. Experiment $1 \mathrm{~A}$ demonstrated that readers make accurate judgments about the concomitants of the passage of time. Experiment 1B suggested that the match of story outcomes to readers' expectations had a consistent effect on participants' reading times. We designed the second phase of the research to demonstrate the impact of readers' plot-driven analyses. To do this, we altered our stories to create strong reader preferences for particular outcomes. In Experiment 2A, those preferences had a consistent impact on readers' judgments of what were and were not likely outcomes. Experiment 2B demonstrated a similar effect of preferences on the time course of reading. Taken together, this set of experiments demonstrates that readers are fully able to attend to the reality of the passage of time. However, that reality is malleable with respect to the imperatives of plot.

\section{EXPERIMENT 1 Readers' Reality-Driven Analyses}

We designed Experiment 1 to demonstrate that readers' judgments about story outcomes are reality-driven with respect to the passage of time. We wrote stories that ended with a time shift of either short duration (a minute later) or long duration (an hour later). We also wrote outcome sentences for each story. These outcome sentences were consistent with either a short time shift or a long time shift (for examples, see Table 1). The participants read each of these stories, followed by an outcome sentence. In Experiment $1 \mathrm{~A}$, we asked the readers to judge whether the outcome sentence was sensible following the story. Our prediction for this experiment relied on the suggestion that readers develop and apply reality-driven temporal constraints as they understand these stories. As such, partici- 
Table 1

Sample Stories and Outcome Sentences From Experiment 1

\section{Story and Time Shifts}

Margaret had to hurry when the hotel forgot to give her a wake-up call.

Margaret had been staying in the hotel as part of a short overnight layover before the next morning's early flight to her final destination.

Margaret threw all of her clothes into her luggage bag.

Then she took the elevator down to the lobby of the hotel.

Margaret finished gulping down her coffee and ran out to the taxi stand.

A cab driver put her luggage in the trunk and she took a seat inside the cab.

"To the airport, and step on it," she said.

The cab drove sixty miles per hour the entire route and approached the airport terminal.

(M) A minute later the airplane took off. (minute time shift)

(H) An hour later the airplane took off. (hour time shift)

\section{Story Outcomes}

Margaret missed her flight. (minute-consistent)

Margaret made her flight. (hour-consistent)

\section{Comprehension Question}

Margaret drank some coffee while riding in the taxi. (False)

\section{Story and Time Shifts}

In the 1950s, a group of four men decided to form a singing troupe called the Jingles.

The Jingles were a group of four young men that sang pop songs during the early days of television.

Early in the Jingles' careers, they had a chance to perform on the American Bandstand television program.

The show, hosted by Dick Clark, was literally watched by millions around the country.

Being seen on the program would guarantee the success of an up and coming band.

Television was beginning to become available in households across America.

The same day, the President of the United States was going to interrupt television programming to discuss current developments in the Korean War.

Dick Clark introduced the Jingles, and they came out for a brief interview early in the program.

A minute later the President interrupted the program. (minute time shift)

An hour later the President interrupted the program. (hour time shift)

\section{Story Outcomes}

The Jingles never received the opportunity to sing. (minute-consistent)

The Jingles' performance was shown across the nation. (hour-consistent)

Comprehension Question

The Jingles gave a short interview before performing. (True)

pants should more readily accept outcome sentences that are consistent with a matching time shift.

In Experiment 1B, we assessed the extent to which readers' temporal analyses have an influence on reading times. Previous research has suggested that reading times are sensitive to the consistency between events early in a text and subsequent information (Albrecht \& O'Brien, 1993; Cook, Halleran, \& O’Brien, 1998; O'Brien, Rizzella, Albrecht, \& Halleran, 1998; Rapp, Gerrig, \& Prentice, 2001). For example, Albrecht and O'Brien demon- strated that participants exhibited slower reading times when a characters' actions late in a text (e.g., "Mary ordered a cheeseburger and fries.") contradicted information given early in the text (e.g., "Mary, a health nut, has been a strict vegetarian for 10 years."). In Experiment 1B, the participants read stories that ended with explicit outcome sentences. We predicted that readers would generate reality-driven expectations to a sufficient criterion that their reading times would be increased for outcome sentences that did not match reality-driven expectations for time shifts.

Although Experiment $1 \mathrm{~A}$ addresses whether readers are able to make accurate judgments about what types of events are likely to transpire in different amounts of time (i.e., a minute vs. an hour), Experiment $1 \mathrm{~B}$ need not provide a parallel finding. Specifically, it could easily be the case that participants would read and accept an outcome without expending the effort to determine whether the outcome was compatible with an overarching temporal model. Readers could, for example, accept the narrator's assertion, "Billy got Mark McGwire's autograph" without attempting to integrate that outcome with the previous statement, "A minute later he got into his limo and rode off." As we have indicated, we predict that readers will attempt such an integration. If our prediction is confirmed, Experiment 1B will provide evidence that readers are, in fact, engaging in some type of analysis to determine if the episodes are temporally coherent.

\section{Method}

Participants. Twenty-four Stony Brook undergraduates participated in Experiment 1A, and twenty-four in Experiment 1B, for class credit. All participants were native speakers of English.

Apparatus. The experiments were run on two IBM-compatible 486 personal computers that recorded responses and judgment latencies. The participants were seated in front of a MicroScan color monitor with their hands resting on the keyboard. They used buttons on the keyboard to make appropriate responses. The sentences were displayed in the center of the screen in standard upper- and lowercase type.

Materials. To begin this series of experiments, we wrote 24 stories. These stories were each 10 sentences long. The first 8 sentences introduced a character (or group of characters) and a scenario (e.g., Brad and a malfunctioning computer, Charles trying to get airline tickets, the Jingles trying to perform on national television). The 9th sentence indicated a time shift by using either a minute later or an hour later. A final sentence followed the time shift, describing the outcome of the story. There were two versions of the outcome sentence for each story. A minute-consistent outcome was more likely to have occurred if only a minute of story time had passed; an hourconsistent outcome was more likely if an hour of story time had passed. We equated the number of words for the two versions of the outcome sentence.

We conducted an off-line norming study to ensure that readers found the outcomes to be reasonable given the time constraints (e.g., that the minute outcome could, in reality, transpire in a minute). We asked 54 native English-speaking Stony Brook undergraduates to read one version of each story and indicate whether they thought the outcome sentence accurately described what they felt could happen next. There were six versions of each item (minute vs. 10-minute vs. hour time shift, minute-consistent vs. hour-consistent outcome sentence). (We included a 10-minute time shift to serve as baseline data for a future experiment.) Using a Latin-square design, we placed one 
of the six versions of each item on one of six questionnaires. Each participant read 24 stories, 6 of each type. The instructions read, "At the end of each story, you'll be asked to decide the likelihood of the final outcome. ... Using a scale rating from 1 to 9 , we would like you to tell us how accurate you think the sentence is in describing what happens next." The endpoints of the scale were labeled 1 (not at all what happens next) and 9 (exactly what happens next).

Mean agreement rates for the time shift sentences are presented in Table 2. The data suggest that we were successful at creating time shifts that differentiated the outcome sentences. To assess the reliability of this finding, we carried out analyses with both participants $\left(F_{1}\right)$ and items $\left(F_{2}\right)$ as random variables. Those analyses revealed a reliable interaction between time shifts and outcome sentences $\left[F_{1}(2,96)=67.71, M S_{\mathrm{e}}=2.603, p<.001 ; F_{2}(2,46)=114.30\right.$, $\left.M S_{\mathrm{e}}=0.658, p<.001\right]$. Matching conditions (e.g., minute time shift with minute-consistent outcome and hour time shift with hourconsistent outcome) yielded higher agreement ratings than did nonmatching conditions (e.g., minute time shift with hour-consistent outcome and hour time shift with minute-consistent outcome). The 10-minute time shifts yielded agreement ratings that fell between these matching and nonmatching conditions. There were no significant main effects for either time shifts or outcome sentences (all $F \mathrm{~s}<1.65)$. These data suggest that our stories successfully instantiated appropriate reality-driven expectations about the passage of time.

We also wrote 24 filler stories without time shifts. The filler stories included outcomes that were not dependent on the passage of time. There was only one version of each filler item. In addition, for Experiment 1B, we wrote comprehension questions for each of our experimental and filler stories, to test the readers' basic knowledge for the events in the stories (see Table 1 for a sample).

Design. For Experiments 1A and 1B, the stories and outcome sentences were the same as those used in the norming study. Overall, there were four versions of each story based on the 24 stories, as a function of time shift and outcome sentence (see Table 1 for examples). Using a Latin-square design, we constructed four lists of stories so that each story appeared in a different version on each list. The filler stories were added to each of the lists. Each list was split in half and presented in random order to the participants in two blocks, one immediately following the other. The lists were split in order to allow the participants a short break after reading half of the stories. For both Experiments $1 \mathrm{~A}$ and $1 \mathrm{~B}$, each participant read one version of each story and all filler items in a different random order (within each half), for a total of 48 stories. In Experiment 1B, each story concluded with a comprehension question. Comprehension questions for each list were counterbalanced so that half of each list contained 12 true and 12 false statements.

Procedure. For Experiment 1A, participants began with 12 practice stories and outcome sentences in order to become acquainted with the stimulus format and keyboard controls. Each story began with the words "press NEXT for the next story" appearing on the monitor. The participants pressed the "A" key, labeled NEXT, to proceed to the next story. The first sentence of a story appeared on the screen. After reading it, the participants pressed the NEXT key to advance to the next sentence. This sequence was repeated for each of the nine

Table 2

Mean Agreement Ratings in Norming Study for Experiment 1

\begin{tabular}{lccc}
\hline & $\begin{array}{c}\text { Minute-Consistent } \\
\text { Outcome }\end{array}$ & $\begin{array}{c}\text { Hour-Consistent } \\
\text { Outcome }\end{array}$ & Mean \\
\hline Minute time shift & 6.27 & 3.68 & 4.97 \\
10-minute time shift & 4.86 & 4.56 & 4.71 \\
Hour time shift & 3.66 & 6.17 & 4.91 \\
$\quad$ Mean & 4.93 & 4.80 & \\
\hline
\end{tabular}

sentences. After participants pressed the NEXT key following the ninth sentence, a beep sounded from the computer, and an outcome sentence appeared. The participants were instructed to decide whether the outcome sentence made sense, given the story: "It will be your job to decide whether you think this sentence accurately describes what you feel would happen next in the story." The participants indicated YES (i.e., "I agree [that this would happen next]") or NO (i.e., "I disagree [that this would happen next]") by pressing "J" or " $\mathrm{K}$ " on the keyboard. If participants took longer than $3 \mathrm{sec}$ to read and respond to the outcome sentence, a message reading "*** Too SLOW $* * *$ " was displayed on the screen for $4 \mathrm{sec}$.

The procedure was identical for Experiment 1B, with the following modifications, eliminating the overt judgment task. The participants pressed the NEXT key after reading each of the 10 sentences in the entire story. After participants pressed the NEXT key following the 10th sentence (the outcome sentence), a beep sounded from the computer, and a prompt read "*** Think of a title for the story ***" (cf. Gerrig, 1989; Rapp et al., 2001). We asked participants to carry out this task so that they would pay appropriate attention while reading each story. After participants pressed the NEXT key (to indicate that they had thought of a title), another beep sounded, and a comprehension question appeared on the screen. The participants were required to press either a YES (i.e., "Yes, that is true"; "J") or a NO (i.e., "No, that is false"; "Z") key in response to the comprehension question. There was no time limit for responding to the comprehension question.

\section{Results and Discussion}

We will present the data and analyses for Experiment 1A, followed by those for Experiment 1B. Table 3 presents mean agreement rates for Experiment $1 \mathrm{~A}$. We eliminated data from trials on which participants' response latencies were more than three standard deviations above the mean, which included "too slow" trials. ${ }^{1}$ This resulted in a loss of $0.86 \%$ of the data.

For Experiment 1A, we predicted that participants would be more likely to respond yes to outcome sentences consistent with a preceding time shift. To test this, we conducted an analysis of agreement ratings carried out on the proportion of yes responses provided by the participants. As is shown in Table 3, participants were considerably more likely to accept outcomes that were temporally consistent with time shifts $\left[F_{1}(1,20)=199.11, M S_{\mathrm{e}}=0.039\right.$, $\left.p<.001 ; F_{2}(1,20)=312.27, M S_{\mathrm{e}}=0.026, p<.001\right]$. Simple effects tests confirmed this pattern both for stories with minute time shifts [a $64.3 \%$ difference; $F_{1}(1,20)=$ $127.22, M S_{\mathrm{e}}=0.039, p<.001 ; F_{2}(1,20)=190.82, M S_{\mathrm{e}}=$ $0.026, p<.001]$ and for those with hour time shifts [a $49.9 \%$ difference; $F_{1}(1,20)=76.62, M S_{\mathrm{e}}=0.039, p<$ $\left..001 ; F_{2}(1,20)=114.92, M S_{\mathrm{e}}=0.026, p<.001\right]$. Participants also tended to accept more outcomes following hour time shifts $(M=58.7 \%)$ than following minute time shifts $(M=54.3 \%)\left[F_{1}(1,20)=3.99, M S_{\mathrm{e}}=0.031, p=\right.$ $\left..069 ; F_{2}(1,20)=8.38, M S_{\mathrm{e}}=0.051, p<.05\right]$. This suggests that participants were somewhat more likely to judge that an outcome still would not occur after an hour (e.g., after an hour shift, "Billy didn't get the autograph") than that an outcome could occur with insufficient time (e.g., after a minute shift, "Billy got Mark McGwire's autograph").

Table 4 presents mean reading times for outcome sentences in Experiment 1B. We eliminated outlying data 
Table 3

Agreement Rates (Percent Yes Responses) in Experiment 1A

\begin{tabular}{lccr}
\hline & $\begin{array}{c}\text { Minute-Consistent } \\
\text { Outcome }\end{array}$ & $\begin{array}{c}\text { Hour-Consistent } \\
\text { Outcome }\end{array}$ & Mean \\
\hline Minute time shift & 86.4 & 22.1 & 54.3 \\
Hour time shift & 33.7 & 83.6 & 58.7 \\
Mean & 60.1 & 52.9 & \\
\hline
\end{tabular}

falling more than three standard deviations above the mean. This resulted in a loss of $1.21 \%$ of the data.

For Experiment 1B, we predicted that participants' reading times would be slowed when they encountered an inconsistency between reality-driven temporal expectations and the actual story outcome. Specifically, we expected that participants' reading times would increase when they read an outcome sentence that was inconsistent with a previous time shift. Analysis of reading times supported this prediction: Participants were, on average, $140 \mathrm{msec}$ slower to read the outcome sentence if it was inconsistent with an earlier time shift than if it was consistent $\left[F_{1}(1,20)=11.03, M S_{\mathrm{e}}=43,996, p<.005\right.$; $\left.F_{2}(1,20)=9.10, M S_{\mathrm{e}}=58,468, p<.01\right]$. However, simple effects tests revealed that the 212 -msec difference for minute time shifts was reliable $\left[F_{1}(1,20)=12.26, M S_{\mathrm{e}}=\right.$ $43,996, p<.005 ; F_{2}(1,20)=9.22, M S_{\mathrm{e}}=58,468, p<$ $.01]$, whereas the 67 -msec difference for hour time shifts was not $\left[F_{1}(1,20)=1.22, M S_{\mathrm{e}}=43,996, p>.20\right.$; $\left.F_{2}(1,20)=0.92, M S_{\mathrm{e}}=58,468, p>.20\right]$. These simple effects tests suggested that, in moment-by-moment reading, people marshaled stronger expectations for the concomitants of minute time shifts than for those of hour time shifts: Events following an hour's passage of time are less constrained than those following a minute's passage. Recall that, in Experiment 1A, we found symmetrical effects on people's judgments. This contrast suggests that somewhat different constraints were at work during the exigencies of reading. There were no significant main effects of time shift or outcome sentence (all $F_{\mathrm{S}}<1.5$ ).

Overall, these results provide strong evidence that readers engage in reality-driven analyses of the temporal coherence of narrative episodes. They complement Zwaan's (1996) results by showing that readers construct models that are influenced by the temporal coherence of narrative events. We intended the second experiment to confirm that readers' involvement with narratives' plots can bring about modifications of reality-driven judgments.

\section{EXPERIMENT 2 Readers' Plot-Driven Analyses}

We designed the second phase of our project to demonstrate that plot-driven analyses have a consistent impact on readers' use of temporal expectations. We wrote versions of each of our stories that imparted strong reader preferences for particular story outcomes. Recall the sample story from the introduction, which had this second sentence in one of its two versions:
2. Billy had been diagnosed with terminal cancer, and his lifelong dream was to meet his baseball idol.

This version of the story with this material should generate a reader preference that Billy obtain the autograph (i.e., that Billy will have acquired McGwire's signature before McGwire leaves the stadium). We know from our earlier experiments that readers will generally accept the assertion "Billy didn't get the autograph." However, the overall prediction for Experiment 2 is that the readers' plot-driven preferences will prompt them, on some occasions, to reject outcomes that are inconsistent (or accept outcomes that are consistent) with those preferences. In essence, we are predicting that readers' plot-driven analyses - what they need or wish to take place-will render time somewhat more flexible than reality allows.

As in the earlier experiments, participants read stories that ended with either minute or hour time shifts. We expected to find the same general consistency between time shifts and outcomes that we obtained in Experiment 1. However, we also expected a relative change in the data in the direction of the Experiment 2 preferences. For example, in Experiment 2A, we expected the majority of readers to accept the statement "Billy didn't get the autograph" after a minute time shift. However, we expected that majority to be smaller when the narrative had imparted a reader preference that Billy get the autograph (an hour-consistent preference), by comparison with circumstances in which the narrative imparted a reader preference that Billy fail to receive the autograph (a minuteconsistent preference). For Experiment 2B, we expected to find the same pattern of preferences overlaid on Experiment 1B's reality-driven reading time results. Specifically, we expected longer reading times when story outcomes were inconsistent with readers' preferences.

\section{Method}

Participants. Forty-eight Stony Brook undergraduates participated in Experiment 2A, and 48 in Experiment 2B, for class credit. All the participants were native speakers of English.

Apparatus. The apparatus was identical to that used in Experiment 1.

Materials. To evaluate the impact of plot-driven analyses, we added preference information to the narration of each experimental story. We wrote two new versions of the second sentence of each story. These sentences were designed to instantiate either a preference for the minute-consistent outcome (a minute-consistent preference) or a preference for the hour-consistent outcome (an hour-consistent preference) (see Table 5). We equated the lengths of the two versions of the second sentence.

We pretested the revised stories to determine whether the preference statements had the intended impact on readers' preferences. We asked 24 English-speaking Stony Brook undergraduates to read one version

Table 4

Mean Reading Times (in Milliseconds) for Outcome Sentences in Experiment 1B

\begin{tabular}{lccc}
\hline & $\begin{array}{c}\text { Minute-Consistent } \\
\text { Outcome }\end{array}$ & $\begin{array}{c}\text { Hour-Consistent } \\
\text { Outcome }\end{array}$ & Mean \\
\hline Minute time shift & 1,881 & 2,093 & 1,987 \\
Hour time shift & 2,081 & 2,014 & 2,048 \\
Mean & 1,981 & 2,054 & \\
\hline
\end{tabular}


Table 5

Sample Stories and Outcome Sentences From Experiment 2

\section{Minute-Consistent Preference}

\section{Story and Time Shifts}

Andre and his wife had been arguing again, but this time things had gone completely crazy.

Andre continually abused his helpless wife Karen, and now he was going to really give her a beating.

Andre managed to grab the gun out of Karen's hands.

He wiped sweat from his brow and began stepping backwards until his back hit the bedroom wall.

Her eyes grew wide as she realized what was about to happen.

Andre's finger gently pressed the trigger of the gun.

Karen fell to the floor in a pool of sticky blood.

Andre knew the police would be here soon, but it was hard to clear his head.

(M) A minute later the cops barged into the room. (minute time shift)

(H) An hour later the cops barged into the room. (hour time shift)

\section{Story Outcomes}

Andre was caught holding a smoking gun. (minute-consistent)

Andre had cleaned the room of evidence. (hour-consistent)

\section{Hour-Consistent Preference}

\section{Story and Time Shifts}

Andre and his wife had been arguing again, but this time things had gone completely crazy.

Andre knew that Karen would hurt the children after murdering him, so he acted quickly to save them.

Andre managed to grab the gun out of Karen's hands.

He wiped sweat from his brow and began stepping backwards until his back hit the bedroom wall.

Her eyes grew wide as she realized what was about to happen.

Andre's finger gently pressed the trigger of the gun.

Karen fell to the floor in a pool of sticky blood.

Andre knew the police would be here soon, but it was hard to clear his head.

(M) A minute later the cops barged into the room. (minute time shift)

(H) An hour later the cops barged into the room. (hour time shift)

\section{Story Outcomes}

Andre was caught holding a smoking gun. (minute-consistent)

Andre had cleaned the room of evidence. (hour-consistent)

\section{Comprehension Question}

Andre grabbed the knife out of Karen's hands. (False)

of each story containing a sentence imparting a minute-consistent, an hour-consistent, or a neutral preference. (The neutral versions used the original sentences from Experiment 1.) The pretest stories ended before the time shifts. In parallel to procedures used by Allbritton and Gerrig (1991) to norm their preference stimuli, each story was followed by both outcome sentences. Participants were asked to decide which of the two possible outcomes, labeled "A" and "B," they would rather have happen. Outcomes were randomly ordered between items. One version of each story was placed into one of three questionnaires . Each participant read 24 stories, 8 of each type. The instructions read, "Using a scale rating from 1 to 9 , we would like you to tell us which outcome you would rather have happen." The scale was labeled 1 ( $\operatorname{prefer} A$ ), 5 (neutral), and 9 ( prefer B).

The data were transformed so that 1 represented a preference for a minute-consistent outcome and 9 represented a preference for an hour-consistent outcome. Participants preferred hour-consistent outcomes following hour-consistent preferences $(M=6.98)$ and minute-consistent outcomes following minute-consistent preferences $(M=4.26)$. Participants' preferences following neutral statements fell between positive and negative outcomes $(M=6.14)$. These means differed reliably from one another $\left[F_{1}(2,42)=19.53, M S_{\mathrm{e}}=4.759\right.$, $\left.p<.001 ; F_{2}(2,44)=65.78, M S_{\mathrm{e}}=1.815, p<.001\right]$. These pretest data suggest that the preference statements successfully instantiated suitable preferences for outcomes.

Design. There were eight versions of each of the 24 stories, as a function of outcome preference, time shift, and outcome sentence (see Table 5 for an example). Using a Latin-square design, we constructed eight lists of stories so that each story appeared in a different version on each list. The filler items were added to each of the lists. Each list was split in half and presented in random order to participants in two blocks, one immediately following the other. The lists were split in order to allow the participants a short break after reading half of the stories. For both Experiments $2 \mathrm{~A}$ and 2B, each participant read one version of each story and all filler items in a different random order (within each half), for a total of 48 stories. In Experiment $2 \mathrm{~B}$, each story concluded with a comprehension question. Comprehension questions for each list were counterbalanced so that half of each list contained 12 true and 12 false statements.

Procedure. The procedure for Experiment 2A was identical to that used in Experiment 1A, and the procedure for Experiment $2 \mathrm{~B}$ was identical to that used in Experiment 1B.

\section{Results and Discussion}

Table 6 presents mean agreement rates for Experiment $2 \mathrm{~A}$. We eliminated trials on which participants' response latencies were more than three standard deviations above the mean. This resulted in a loss of $0.87 \%$ of the data.

The agreement ratings analyses were carried out on the proportion of participants' yes responses. As in Experiment $1 \mathrm{~A}$, we predicted that participants would prefer outcomes that matched time shifts. The data confirmed this prediction: On average, participants were $35 \%$ more likely to agree with story outcomes that matched preceding time shifts $\left[F_{1}(1,40)=140.78, M S_{\mathrm{e}}=0.080, p<.001\right.$; $\left.F_{2}(1,16)=120.24, M S_{\mathrm{e}}=0.045, p<.001\right]$. Simple effects tests confirmed this pattern both for stories with minute time shifts [a $46.5 \%$ difference; $F_{1}(1,40)=$ $143.32, M S_{\mathrm{e}}=0.080, p<.001 ; F_{2}(1,16)=254.79$, $\left.M S_{\mathrm{e}}=0.045, p<.001\right]$ and for those with hour time shifts [a $22.2 \%$ difference; $F_{1}(1,40)=59.56, M S_{\mathrm{e}}=0.080, p<$ $\left..001 ; F_{2}(1,16)=105.89, M S_{\mathrm{e}}=0.045, p<.001\right]$.

However, we also predicted that participants would provide higher agreement ratings when story outcomes matched preferences. Again, the data confirmed this prediction: On average, participants were $17 \%$ more likely to agree with story outcomes if they were consistent with

Table 6

Agreement Rates (Percent Yes Responses) in Experiment 2A

\begin{tabular}{|c|c|c|c|}
\hline & $\begin{array}{l}\text { Minute-Consistent } \\
\text { Outcome }\end{array}$ & $\begin{array}{l}\text { Hour-Consistent } \\
\text { Outcome }\end{array}$ & Mean \\
\hline \multicolumn{4}{|c|}{ Minute-Consistent Preference } \\
\hline Minute time shift & 89.5 & 29.9 & 59.7 \\
\hline Hour time shift & 56.2 & 57.6 & 56.9 \\
\hline Mean & 72.9 & 43.8 & \\
\hline \multicolumn{4}{|c|}{ Hour-Consistent Preference } \\
\hline Minute time shift & 69.0 & 35.6 & 52.3 \\
\hline Hour time shift & 43.6 & 86.6 & 65.1 \\
\hline Mean & 56.3 & 61.1 & \\
\hline
\end{tabular}


preferences than if they were inconsistent $\left[F_{1}(1,40)=\right.$ $38.94, M S_{\mathrm{e}}=0.072, p<.001 ; F_{2}(1,16)=24.27, M S_{\mathrm{e}}=$ $0.052, p<.001]$. Simple effects tests suggested that the effect of preference was more robust when the stories imparted preferences for the minute-consistent outcomes [a $29.2 \%$ difference; $F_{1}(1,40)=112.91, M S_{\mathrm{e}}=0.072, p<$ $\left..001 ; F_{2}(1,16)=156.33, M S_{\mathrm{e}}=0.052, p<.001\right]$ than for the hour-consistent outcomes [a $4.8 \%$ difference; $F_{1}(1,40)=3.07, M S_{\mathrm{e}}=0.072, p<.10 ; F_{2}(1,16)=4.25$, $\left.M S_{\mathrm{e}}=0.052, p<.10\right]$.

We also obtained a reliable interaction between preferences and time shifts $\left[F_{1}(1,40)=6.94, M S_{\mathrm{e}}=0.079\right.$, $\left.p<.05 ; F_{2}(1,16)=8.88, M S_{\mathrm{e}}=0.040, p<.01\right]$. The three-way interaction of preference, time shift, and story outcome failed to reach significance $(F<2.1)$. Participants were somewhat more likely to agree with minuteconsistent outcomes $(M=64.7 \%)$ versus hour-consistent outcomes $(M=52.5 \%)\left[F_{1}(1,40)=23.43, M S_{\mathrm{e}}=0.060\right.$, $\left.p<.05 ; F_{2}(1,16)=4.01, M S_{\mathrm{e}}=0.154, p=.062\right]$.

As in earlier experiments, these results confirm the view that readers' judgments about the likelihood of story outcomes are constrained by temporal reality. However, the data also support our suggestion that plot-driven preferences will, on some occasions, modify those temporal judgments. For example, in Experiment 1A, the readers preferred minute-consistent story outcomes (e.g., "Billy didn't get the autograph"), on average, $86 \%$ of the time if they followed a matching time shift (e.g., "A minute later he got into his limo and rode off."). However, in Experiment $2 \mathrm{~A}$, these agreement ratings fell to $69 \%$ after the story instantiated a preference for an hour-consistent outcome.

Table 7 presents mean reading times for the outcome sentences in Experiment 2B. We eliminated data falling more than three standard deviations above the mean. This resulted in a loss of $0.26 \%$ of the data.

For Experiment 2B, we predicted that participants' reading times would be slowed when they were presented with an outcome sentence that was inconsistent with their temporal models. This prediction was confirmed: On average, participants were $220 \mathrm{msec}$ slower to read outcome sentences that were inconsistent with the preceding time shift than if they were consistent $\left[F_{1}(1,40)=18.05, M S_{\mathrm{e}}=\right.$ $206,929, p<.001 ; F_{2}(1,16)=22.22, M S_{\mathrm{e}}=102,171$,

Table 7

Mean Reading Times (in Milliseconds) for Outcome Sentences in Experiment 2B

\begin{tabular}{|c|c|c|c|}
\hline & $\begin{array}{c}\text { Minute-Consistent } \\
\text { Outcome }\end{array}$ & $\begin{array}{l}\text { Hour-Consistent } \\
\text { Outcome }\end{array}$ & Mean \\
\hline \multicolumn{4}{|c|}{ Minute-Consistent Preference } \\
\hline Minute time shift & 1,995 & 2,565 & 2,280 \\
\hline Hour time shift & 1,964 & 2,125 & 2,045 \\
\hline Mean & 1,980 & 2,345 & \\
\hline \multicolumn{4}{|c|}{ Hour-Consistent Preference } \\
\hline Minute time shift & 1,990 & 1,988 & 1,989 \\
\hline Hour time shift & 2,524 & 2,050 & 2,287 \\
\hline Mean & 2,257 & 2,019 & \\
\hline
\end{tabular}

$p<.001]$. This result replicates Experiment 1B. However, unlike Experiment 1B, simple effects tests confirmed this pattern both for stories with minute time shifts [a 284-msec difference; $F_{1}(1,40)=57.33, M S_{\mathrm{e}}=206,929$, $\left.p<.001 ; F_{2}(1,16)=116.10, M S_{\mathrm{e}}=102,171, p<.001\right]$ and for those with hour time shifts [a 157-msec difference; $F_{1}(1,40)=42.71, M S_{\mathrm{e}}=206,929, p<.001 ; F_{2}(1,16)=$ $\left.86.49, M S_{\mathrm{e}}=102,171, p<.001\right]$.

We also predicted that participants' reading times would increase with mismatches between reader preferences and story outcomes. The data supported this prediction: On average, the participants were $302 \mathrm{msec}$ slower to read outcome sentences that were inconsistent with the reader preference than if they were consistent $\left[F_{1}(1,40)=30.83, M S_{\mathrm{e}}=272,737, p<.001 ; F_{2}(1,16)=\right.$ $\left.26.35, M S_{\mathrm{e}}=168,911, p<.001\right]$. Simple effects tests suggest that the effect of preferences was reliable both for stories that imparted preferences for minute outcomes [a 365 -msec difference; $F_{1}(1,40)=47.02, M S_{\mathrm{e}}=272,737$, $\left.p<.001 ; F_{2}(1,16)=75.92, M S_{\mathrm{e}}=168,911, p<.001\right]$ and for those that imparted preferences for hour outcomes [a 238-msec difference; $F_{1}(1,40)=19.94, M S_{\mathrm{e}}=$ $272,737, p<.001 ; F_{2}(1,16)=32.19, M S_{\mathrm{e}}=168,911$, $p<.001]$.

There was also a significant interaction between reader preferences and time shifts $\left[F_{1}(1,40)=45.32, M S_{\mathrm{e}}=\right.$ $131,986, p<.001 ; F_{2}(1,16)=35.93, M S_{\mathrm{e}}=94,152, p<$ $.001]$. Table 7 suggests the origin of this result: Participants were slowest reading the outcome sentences when the time shift was consistent with the preference (e.g., the readers preferred and the story delivered a minute time shift) but the outcome was consistent with neither (e.g., the stated outcome was the hour outcome). There were no other reliable effects.

The overall results of Experiment 2 support our suggestion that readers' plot-driven preferences have an impact on the expectations they generate for story outcomes. In Experiment 2A, readers' overt judgments about the relationship between time shifts and likely outcomes were affected by plot-driven preferences. In Experiment 2B, although participants' reading times displayed sensitivity to the consistency between time shifts and outcomes, those reading times also provided evidence of an overlaid impact of consistency with preferences.

\section{GENERAL DISCUSSION}

The goal of this research was to demonstrate an interaction between readers' reality-driven and plot-driven analyses of likely narrative outcomes. In our first pair of experiments, readers used reality-driven analyses to structure their expectations: Both their overt judgments and reading times reflected assessments of the concomitants of the passing of time that were consistent with realworld constraints. When, for example, only a minute had passed but the narrative asserted that an hour's worth of events had transpired, participants showed consistent increases in their time to understand the stories. Our second pair of experiments demonstrated that, even so, readers' 
plot-driven preferences for particular outcomes wield an influence on narrative experiences: Again, both overt judgments and reading times reflected a shift such that readers showed a propensity to accept that their preferred outcome might have happened despite reality-driven constraints. We take the overall pattern of data to support our view that readers' narrative experiences are affected by the imperatives of both reality and plot.

Our experiments took as their starting point theories of situation models, such as the event-indexing model, that make concrete predictions about the dimensions readers regularly encode during narrative experiences (Zwaan, Langston, \& Graesser, 1995; Zwaan, Magliano, \& Graesser, 1995). In that context, we believe that our first pair of experiments further contributes to the literature that suggests that readers are attentive to temporal relationships when they create representations of texts. The question, then, becomes how exactly the preferences our stories instantiated (in Experiment 2) brought about the shifts in readers' judgments and reading times. In the introduction, we suggested that preferences might have an impact on the way in which readers construct their mental simulations: Readers could imagine fitting less or more activity into an interval of time, depending on their plot-driven predilections. A related alternative would be that, in the face of preferences, readers work less diligently to simulate counterevidence. Consider, for example, circumstances in which McGwire leaves the stadium after a minute. Suppose the narration asserts "Billy got Mark McGwire's autograph." In the absence of a preference, we would expect readers to be skeptical (as they were in Experiment 1 ) because they cannot easily imagine how, in a minute's time, that could be the case. In the presence of a preference, we are suggesting either that readers might simulate a scene in which Billy stands out and/or that they might not work as hard to simulate the scene at all. When they get the outcome they desire, readers might disengage the ordinary impulse to construct or evaluate the coherence of a text along a particular dimension (in this case, the temporal dimension).

We have suggested that our plot-driven results arise from readers' hopes and preferences. An alternative possibility is that the preferences were creating "good guys" and "bad guys" and that the readers were engaging generic expectations for who should win or lose. Recall, for example, the opening excerpt from Thunderball. We suggested that readers' plot-driven analyses lead them to hope, against the reality of his situation, that Bond will survive. Perhaps what is at work here is not a hope but the strong expectation, based on past experience, that Bond is indestructible. However, if this were the case, it would be hard to explain why readers experience suspense-which they do (Gerrig, 1989, 1993). Readers' ongoing feelings of suspense suggest that the expectation that Bond cannot die does not function in their moment-by-moment experience of the narrative. To access the "fact" that Bond cannot perish, readers must purposefully remove themselves from the narrative world. We argue, similarly, that the readers did not remove themselves from the narrative worlds of our experimental stories to encode and apply generic expectations about "good guys" versus "bad guys." In parallel to earlier research, we suggest that readers' hopes and preferences heighten feelings of suspense and the urgency of the outcomes (Gerrig, 1993).

When we defined plot-driven analyses in the introduction, we suggested that readers are likely to undertake these types of analyses quite regularly, but that different instances of plot-driven analyses will require different mental processes and representations. We conclude by briefly returning to that observation. For our experiments, we have suggested that readers' preferences prompted them to act toward identical texts (i.e., the parts of the texts subsequent to the preference material) in quite different ways. However, we categorized our preferences as only positive or negative. Suppose we varied the intensity of preferences within categories. We would be likely to find that readers would expend more effort (or different types of effort) when the preferences were particularly strong. We would imagine, for example, that readers would be particularly intent on their plot-driven analyses in life-ordeath circumstances, such as James Bond's Thunderball dilemma. We use this example to reinforce our suggestion that plot-driven analyses will give rise to diverse processes and representations. An understanding of this diversity must be a precursor to a complete cognitive psychological account of readers' experiences of narratives.

\section{REFERENCES}

Albrecht, J. E., \& O'Brien, E. J. (1993). Updating a mental model: Maintaining both local and global coherence. Journal of Experimental Psychology: Learning, Memory, \& Cognition, 19, 1061-1070.

Allbritton, D. W., \& Gerrig, R. J. (1991). Participatory responses in text understanding. Journal of Memory \& Language, 30, 603-626.

Barsalou, L. W. (1999). Perceptual symbol systems. Behavioral \& Brain Sciences, 22, 577-660.

Cook, A. E., Halleran, J. G., \& O'Brien, E. J. (1998). What is readily available during reading? A memory-based view of text processing. Discourse Processes, 26, 109-129.

Fleming, I. (1961). Thunderball. New York: Viking.

GERrIG, R. J. (1989). Suspense in the absence of uncertainty. Journal of Memory \& Language, 28, 633-648.

GERRIG, R. J. (1993). Experiencing narrative worlds. New Haven: Yale University Press.

Glenberg, A. M., \& Mathew, S. (1992, December). When minimalism is not enough: Mental models in reading comprehension. Psycoloquy [On-line serial], 3(64).

Glenberg, A. M., Meyer, M., \& Lindem, K. (1987). Mental models contribute to foregrounding during text comprehension. Journal of Memory \& Language, 26, 69-83.

Graesser, A. C., Kassler, M. A., Kreuz, R. J., \& Mclain-Allen, B. (1998). Verification of statements about story worlds that deviate from normal conceptions of time: What is true about Einstein's dreams? Cognitive Psychology, 35, 246-301.

Kahneman, D., \& Tversky, A. (1982). The simulation heuristic. In D. Kahneman, P. Slovic, \& A. Tversky (Eds.), Judgment under uncertainty: Heuristics and biases (pp. 201-208). New York: Cambridge University Press.

Magliano, J. P., Miller, J., \& ZwaAn, R. A. (2001). Indexing space and time in film understanding. Applied Cognitive Psychology, 15, 533-545.

O’Brien, E. J., Rizzella, M. L., Albrecht, J. E., \& Halleran, J. G. 
(1998). Updating a situation model: A memory-based text processing view. Journal of Experimental Psychology: Learning, Memory, \& Cognition, 24, 1200-1210.

Perrig, W., \& Kintsch, W. (1985). Propositional and situational representations of text. Journal of Memory \& Language, 24, 503-518.

Prentice, D. A., Gerrig, R. J., \& Bailis, D. S. (1997). What readers bring to the processing of fictional texts. Psychonomic Bulletin \& Review, 4, 416-420.

Radvansky, G. A., Zwaan, R. A., Federico, T., \& Franklin, N. (1998). Retrieval from temporally organized situation models. Journal of Experimental Psychology: Learning, Memory, \& Cognition, 24, 1224-1237.

Rapp, D. N., Gerrig, R. J., \& Prentice, D. A. (2001). Readers' traitbased models of characters in narrative comprehension. Journal of Memory \& Language, $\mathbf{4 5}, 737-750$.

Rich, S. S., \& TAYLOR, H. A. (2000). Not all narrative shifts function equally. Memory \& Cognition, 28, 1257-1266.

Rinck, M., HÄHNEL, A., \& Becker, G. (2001). Using temporal information to construct, update, and retrieve situation models of narratives. Journal of Experimental Psychology: Learning, Memory, \& Cognition, 27, 67-80.

TAYLOR, H. A., \& Tversky, B. (1997). Indexing events in memory: Evidence for index dominance. Memory, 5, 509-542.

VAN DiJK, T. A., \& KinTSCH, W. (1983). Strategies of discourse comprehension. New York: Academic Press.
ZWAAN, R. A. (1996). Processing narrative time shifts. Journal of Experimental Psychology: Learning, Memory, \& Cognition, 22, 1196-1207.

Zwaan, R. A., Langston, M. C., \& Graesser, A. C. (1995). The construction of situation models in narrative comprehension: An eventindexing model. Psychological Science, 6, 292-297.

Zwaan, R. A., Madden, C. J., \& Whitten, S. N. (2000). The presence of an event in the narrated situation affects its availability to the comprehender. Memory \& Cognition, 28, 1022-1028.

Zwaan, R. A., Magliano, J. P., \& Graesser, A. C. (1995). Dimensions of situation model construction in narrative comprehension. Journal of Experimental Psychology: Learning, Memory, \& Cognition, 21, 386-397.

ZwAan, R A., \& Radvansky, G. A. (1998). Situation models in language comprehension and memory. Psychological Bulletin, 123, 162-185.

\section{NOTE}

1. We recorded participants' response times in Experiment $1 \mathrm{~A}$ and Experiment 2A to enable us to eliminate trials that were unusually long. We do not report those data because we had no predictions with respect to them, nor did they produce stable patterns.

(Manuscript received July 11, 2001; revision accepted for publication April 22, 2002.) 